\title{
Graduating Students' Evaluations of Their Training and Clinical Performance in Areas of Women's Health in a Chinese Medical School
}

\author{
Margaret Z. Wang, $M D^{1,2}$, Jingyi Fan, $M D^{3}$, IVy Jiang, $M S^{4}$, and Renslow Sherer, $M D^{4}$ \\ 'Pritzker School of Medicine, The University of Chicago, Chicago, IL, USA; '2Department of Psychiatry, University of Texas at Southwestern, Dallas, TX, \\ USA; ${ }^{3}$ Department of Pediatrics, Zhongnan Hospital of Wuhan University, Wuhan, China; ${ }^{4}$ Section of Infectious Disease and Global Health, \\ Department of Medicine, University of Chicago, Chicago, IL, USA.
}

J Gen Intern Med 34(10): 1998-2000

DOI: $10.1007 / \mathrm{s} 11606-019-05090-8$

(c) Society of General Internal Medicine 2019

\section{INTRODUCTION}

China's medical curriculum is undergoing standardization and reform through the $5+3$ model ( 5 years of undergraduate medical studies, 3 years of residency). ${ }^{1,2}$ Few studies have examined the clinical training Chinese medical students receive in women's health. Our study assessed graduating medical students' satisfaction with clinical training and performance in areas of women's health, and compared responses by gender in a major medical school in a provincial capital in China.

\section{METHODS}

This cross-sectional study surveyed 250 fifth-year graduating Chinese medical students from Wuhan University in China, from May to June 2015, following their graduation exam. The survey questions were developed following literature review and input from experts in medical education and the Obstetrics and Gynecology Department at the University of Chicago and Wuhan University on sexual and reproductive health, and cervical and breast cancer screening. Participants could refuse and received no reward for participating. A total of 242 students $($ male $=117$; female $=125)$ completed the survey.

Survey items were either 5-point Likert scale questions measuring satisfactions, where 1 stands for "strongly disagree"; 2, "somewhat disagree"; 3, "neither agree nor disagree"; 4, "somewhat agree"; and 5, "strongly agree." Ratings of " 4 " or " 5 " on the 5-point Likert scale were combined to arrive at percentages of students satisfied with clinical

These findings have been presented in the poster session at the Society of General Internal Medicine, Midwest Regional Meeting, in 2017.

Published online June 13, 2019 training and comfort with clinical ability. Means per rating were calculated for responses. A two-tailed $t$ test using $p<0.05$ was used to test for significance between student responses stratified by gender. The data was collected and analyzed using Excel v14.5.9 (Microsoft $^{\circledR}$ ).

The Institutional Review Boards at Wuhan University and the University of Chicago approved this study.

\section{RESULTS}

Students reported low satisfaction with the adequacy of teaching in counseling about reproductive goals (19.0\%), different forms of contraception (14.4\%), preconception (12.8\%), cervical cancer screening (26.0\%), and performing a breast exam $(45.0 \%)$ (Fig. 1). Over half of the students (62.4\%) were satisfied with the teaching of the pelvic exam.

Less than half of graduating Chinese medical students felt competent to discuss sexual health and reproductive goals $(40.1 \%)$. Students also reported low confidence in educating patients on contraception (20.2\%), counseling patients on preconception care $(27.7 \%)$, screening for cervical cancer $(24.0 \%)$, and performing clinical breast $(45.0 \%)$ or pelvic $(43.5 \%)$ exams.

Student ratings of how well their curriculum prepared them and how comfortable they were in providing care across areas of women's health were stratified by gender (Table 1). Women rated the teaching of cervical cancer screening as more adequate than men $(p<0.002)$. Female students responded they were more confident performing cervical cancer screenings $(p<0.002)$ and clinical breast exams than male students $(p<0.008)$.

\section{DISCUSSION}

Our study found that a majority of graduating medical students in one Chinese provincial capital did not perceive adequate clinical training in fundamental areas of women's health in the 


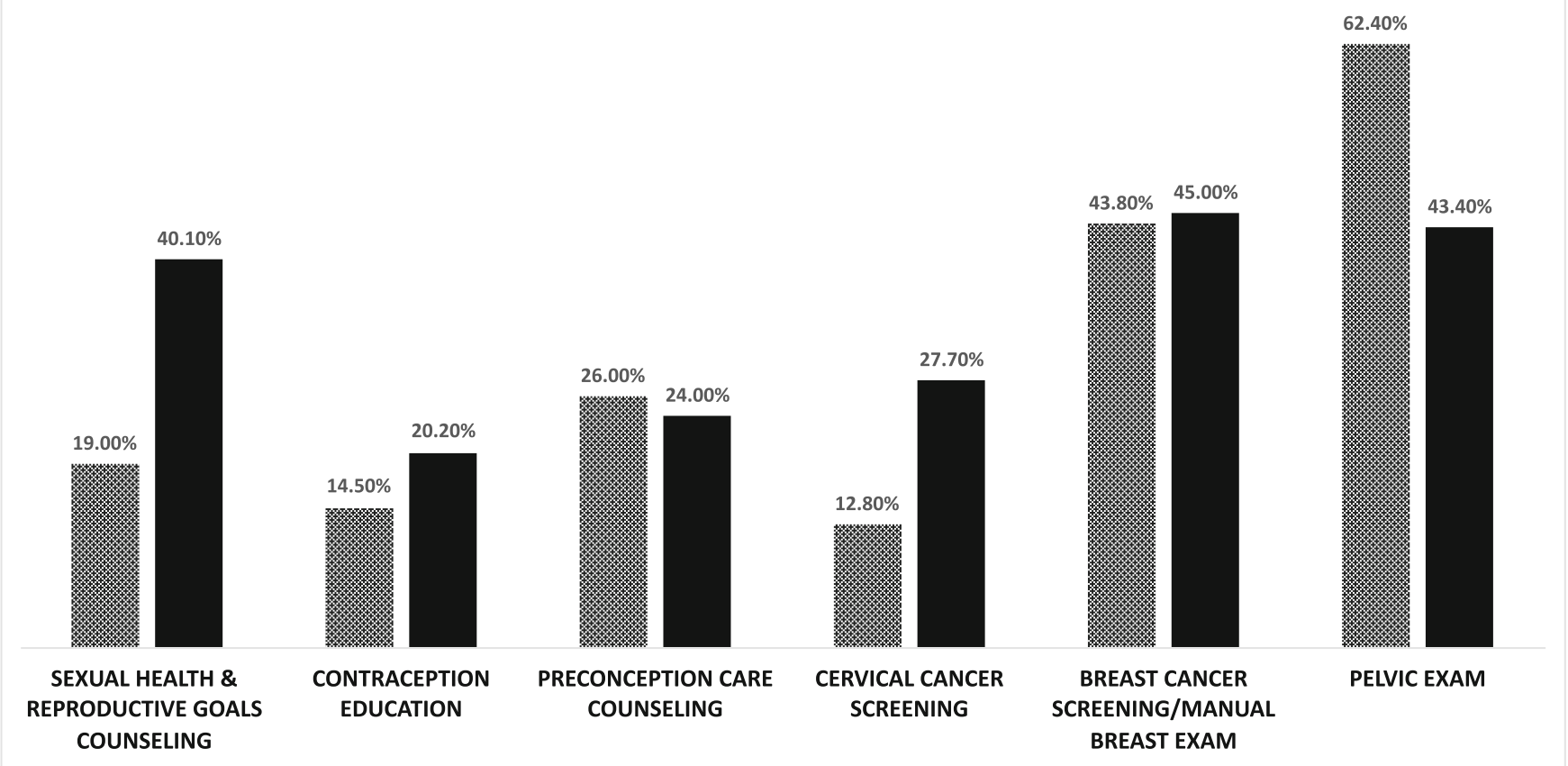

Figure 1 Graduating Chinese students' satisfaction with adequacy of training and competency in topics of women's health. Gray-spotted bars indicate the percentage of graduating medical students surveyed $(N=242)$ satisfied with the level of clinical teaching received in areas of women's health; black solid bars indicate the percentage of graduating medical students surveyed $(N=242)$ comfortable with clinical competency in areas of women's health.

curriculum and rated their clinical abilities in these areas poorly. If additional research shows this to be a nation-wide limitation, medical school curricula in China will need to address these gaps as it undergoes reform. Our findings reflect the nationwide trend of inadequate primary care curricula in Chinese medical schools.

Our study shows that less than half of graduating Chinese medical students in one provincial capital felt confident in clinical skills across areas in women's health, including performing basic cancer screening exams, such as pap smears $(27.2 \%)$ or clinical breast exams $(45.05 \%)$ (Fig. 1). These results support findings at the national level showing low levels of cancer screening knowledge among medical interns even at leading Chinese medical schools. ${ }^{3}$ In 2015 , China's estimated mortality rates for breast and cervical cancers were 69.5 and 30.5 per thousand, respectively. ${ }^{4}$ Furthermore, the mean age of breast cancer diagnosis in Chinese women occurs 10 years earlier than western counterparts due to environmental and genetic differences, ${ }^{5}$ but rates of breast cancer screening and breast care knowledge are still low among Chinese women. ${ }^{6}$ This emphasizes the importance of Chinese medical schools teaching women's health in primary care. Female students were more confident than male students in their clinical abilities to provide cervical cancer and breast cancer screening in our study (Table 1). These findings suggest that reform of Chinese medical education curricula should include more training in women's health and strongly target male medical students and that further investigation of how to establish an encompassing primary care curriculum is needed.

Table 1 Female Versus Male Students' Rating Standard Areas of Women's Health Taught in a Chinese Medical School

\begin{tabular}{|c|c|c|c|c|c|c|}
\hline \multirow[b]{2}{*}{ Area of women's health } & \multicolumn{3}{|c|}{ Ratings of adequacy of training } & \multicolumn{3}{|c|}{ Rating of own clinical ability } \\
\hline & Women, mean & Men, mean & $p$ value & Women, mean & Men, mean & $p$ value \\
\hline Sexual health and reproductive goals & 2.10 & 2.26 & NS & 3.12 & 2.99 & NS \\
\hline Contraception education & 1.92 & 1.85 & NS & 2.46 & 2.59 & NS \\
\hline Cervical cancer screening & 2.60 & 2.01 & $<0.002$ & 2.52 & 1.92 & $<0.002$ \\
\hline Preconception counseling* & 1.90 & 1.92 & NS & 2.79 & 2.65 & NS \\
\hline Breast cancer screening* & 3.25 & 2.90 & NS & 3.43 & 2.96 & $<0.008$ \\
\hline Pelvic exam* & 3.75 & 3.44 & NS & 3.37 & 3.11 & NS \\
\hline
\end{tabular}

The italicized values are significant; the non-italicizied values are not

1 to 5 Likert scale: 1, "strongly disagree"; 5, "strongly agree." NS not significant. *N=241 (missing 1 male response) 
Corresponding Author: Ivy Jiang, MS; Section of Infectious Disease and Global Health, Department of Medicine, University of Chicago, Chicago, IL, USA (e-mail: ijiang@bsd.uchicago.edu).

\section{Compliance with Ethical Standards:}

The Institutional Review Boards at Wuhan University and the University of Chicago approved this study.

Conflict of Interest: The authors declare that they do not have a conflict of interest.

\section{REFERENCES}

1. Zhu J, Li W, Chen L. Doctors in China: improving quality through modernisation of residency education. Lancet. 2016;388(10054):19221929.
2. Blumenthal D, Hsiao W. Lessons from the East - China's Rapidly Evolving Health Care System. NEJM. 2015;372(14):1281-5.

3. Deng L, Na F-F, Wang J-W, Meng M-B, He H-Y, Yang J-J, et al. Insufficient screening knowledge in Chinese interns: a survey in ten leading medical schools. Asian Pac J Cancer Prev. 2011;12(10):2801-2806.

4. Chen W, Zheng R, Baade PD, Zhang S, Zeng H, Bray F, et al. Cancer statistics in China, 2015. CA Cancer J Clin 2016;66(2):115-32.

5. Song Q-K, Li J, Huang R, Fan J-H, Zheng R-S, Zhang B-N, et al. Age of diagnosis of breast cancer in China: almost 10 years earlier than in the United States and the European Union. Asian Pac $\mathrm{J}$ Cancer Prev. 2014; 15(22): 10021-5.

6. Wang B, He M, Wang L, Engelgau MM, Zhao W, Wang L. Breast cancer screening among adult women in China, 2010. Prev Chronic Dis. 2013;10: E183.

Publisher's Note: Springer Nature remains neutral with regard to jurisdictional claims in published maps and institutional affiliations. 